socially in a healthy and normal manner and in conditions of freedom and dignity;

24. Welcome the important role played by national institutions in the genuine and constructive promotion of human rights, and believe that the conceptualization and eventual establishment of such institutions are best left for the States to decide;

25. Acknowledge the importance of cooperation and dialogue between governments and non-governmental organizations on the basis of shared values as well as mutual respect and understanding in the promotion of human rights, and encourage the nongovernmental organizations in consultative status with the Economic and Social Council to contribute positively to this process in accordance with Council Resolution 1296 (XLIV);

26. Reiterate the need to explore the possibilities of establishing regional arrangements for the promotion and protection of human rights in Asia;

27. Reiterate further the need to explore ways to generate international cooperation and financial support for education and training in the field of human rights at the national level and for the establishment of national infrastructures to promote and protect human rights if requested by States;

28. Emphasize the necessity to rationalize the United Nations human rights mechanism in order to enhance its effectiveness and efficiency and the need to ensure avoidance of the duplication of work that exists between the treaty bodies, the SubCommission on Prevention of Discrimination and Protection of Minorities and the Commission on Human Rights, as well as the need to avoid the multiplicity of parallel mechanisms;

29. Stress the importance of strengthening the United Nations Centre for Human Rights with the necessary resources to enable it to provide a wide range of advisory services and technical assistance programmes in the promotion of human rights to requesting States in a timely and effective manner, as well as to enable it to finance adequetely other activities in the field of human rights authorized by competent bodies;

30. Call for increased representation of the developing countries in the Centre for Human Rights.

\title{
INTRA-CHINESE AGREEMENTS*
}

\section{Singapore, 29 April 1993}

\section{INTRODUCTORY NOTE}

In 1991 unofficial bodies have been established by the governments on the Chinese mainland as well as on the Island of Taiwan to serve as instruments for mutual contact. The mainland organization is the Association for Relations Across the Taiwan Straits (ARATS) and the one at Taiwan is the Straits Exchange Foundation (SEF).

In 1992 the two chairmen agreed to hold a meeting to discuss matters of mutual concern to both organizations. A first preparatory meeting by representatives was held on 11 April

* Courtesy of Mr. YANG SHENG-Tsung, Taipei 
1993, followed by a second one on 25-26 April 1993. The formal talks between the chairmen took place from 27 to 29 April 1993.

The four agreements concluded between ARATS and SEF were: (1) a Joint Agreement; (2) an Agreement on Use and Verification of Certificates of Authentication Across the Taiwan Straits; (3) an Agreement on Matters Concerning Inquiry and Compensation for Registered Mail Across the Taiwan Straits; (4) an Agreement on the System for Contacts and Meetings between SEF and ARATS. The first and fourth Agreements are reproduced below in part.

Because of the existing differences in style between the parties and because of the existing political sensitivities, the agreements have been written in two versions with, inter alia, different precedence in referring to each party and different dating systems. The English translation below has been received from the Taiwanese side. The Editors have neglected the exact differences in form between the two versions.

\section{JOINT AGREEMENT}

... The two parties reached the following agreements:

\section{Agenda of Discussions for This Year}

The two parties will definitely hold, by the end of this year, administrative [nonpolitical and functional] discussions on the following topics: repatriation of people who enter the area of the other side in violation of relevant regulations [illegal migrants] and related questions; questions concerning joint efforts to suppress the criminal activities of marine smuggling and robbery; handling of marine fishing disputes between the two sides; protection of intellectual property of the two sides; and mutual assistance between the judicial organs of the two sides (contact and assistance between relevant courts of the two sides).

\section{Economic Exchanges}

Both parties concur in the necessity of strengthening economic exchanges between the two sides for their mutual benefit. Both parties agree to select times and places to continue discussions on the issue of protecting Taiwan business investment in the mainland and related questions, as well as mutual visits of people from industrial and commercial circles.

\section{Exploitation and Exchange [Cooperation] in Energy and Resources}

Both parties agree to hold discussions on strengthening cooperation in the exploitation of energy and resources. 


\section{Culture, Education, Science, and Technology Exchanges}

Both parties agree to actively promote mutual visits and exchanges of young people, the press and science and technology exchanges between the two sides. The two parties will, by the end of this year, sponsor a young people's talent and art competition and exchange and help realize an exchange between young people and mutual visits of news media executives and senior reporters. Both parties shall promote mutual visits of science and technology personnel, exchange science [and] technology publications, study the unification of terminology in science and the standardization of product specifications, and jointly promote the exchange of technology in computers and other industries. Related matters will be discussed further.

\section{Signing and Entry Into Force}

This joint agreement enters into force thirty days from the date of signing by both parties.

\section{AGREEMENT ON THE SYSTEM FOR CONTACTS AND MEETINGS BETWEEN SEF AND ARATS}

The Straits Exchange Foundation (hereinafter referred to as SEF) and the Association for Relations Across the Taiwan Straits (hereinafter referred to as ARATS), for the purpose of establishing a system for contacts and meetings and having held discussions thereon, reached the following agreements:

\section{Meetings}

Where there is practical need and with the consent of both parties, the SEF and ARATS chairmen will hold meetings concerning the business of the two organizations. The venues and related questions will be settled through further negotiation.

The SEF deputy chairman and ARATS deputy chairman or secretaries general of the two organizations will, in principle, hold a meeting once every six months concerning the business of the two organizations. The meetings will be held in Taiwan and the mainland alternately, or in a third place settled on through discussions.

Deputy secretaries general, department chiefs, and personnel of the rank of director of the two organizations will hold meetings quarterly in selected places in Taiwan or the mainland.

\section{Administrative [non-political and functional] Discussions}

Both parties agree to hold, as soon as possible, exclusive discussions on matters which arise in the course of exchanges between the two sides which need to be discussed, and sign agreements. 


\section{Task Forces}

Both parties agree that they will each set up an economic team and a comprehensive team as business requires.

\section{Emergency Contacts}

Both parties agree that they will each designate their deputy secretaries general as liaison persons for emergencies. They shall contact each other and take appropriate measures in such cases.

\section{Facilitating Entry and Exit}

Both parties agree that, on the grounds established by this agreement, they will mutually facilitate personnel, designated by the two organizations through discussions, in their entry into and exit from the areas of the two sides. This shall include assistance in customs processing and other matters relating to travel. Concrete measures will be settled through discussions.

\section{Execution, Amendment, and Termination of Agreements}

Both parties shall comply with agreements reached. Execution, amendment, or termination of an agreement shall be made with the consent of both parties through negotiation.

\section{Unsettled Matters}

If this agreement leaves any matters unsettled, the two parties may negotiate a settlement through appropriate channels.

\section{Signing and Entry Into Force}

This agreement enters into force 30 days from the date of signing by both parties. 